\title{
A Randomized Trial of Simplified Maintenance Therapy with Abacavir, Lamivudine, and Zidovudine in Human Immunodeficiency Virus Infection
}

\author{
Milos Opravil, ${ }^{1}$ Bernard Hirschel, ${ }^{3}$ Adriano Lazzarin, ${ }^{9}$ \\ Hansjakob Furrer, ${ }^{4}$ Jean-Philippe Chave, ${ }^{5}$ \\ Sabine Yerly, ${ }^{3}$ Leslie R. Bisset, ${ }^{2}$ Marek Fischer, ${ }^{1}$ \\ Pietro Vernazza, ${ }^{6}$ Enos Bernasconi, ${ }^{7}$ Manuel Battegay, ${ }^{8}$ \\ Bruno Ledergerber, ${ }^{1}$ Huldrych Günthard, ${ }^{1}$ \\ Colin Howe, ${ }^{10}$ Rainer Weber, ${ }^{1}$ and Luc Perrin, ${ }^{3}$ \\ for the Swiss HIV Cohort Study ${ }^{a}$
}

\begin{abstract}
Divisions of ${ }^{1}$ Infectious Diseases and ${ }^{2}$ Clinical Immunology, University Hospital, Zurich, ${ }^{3}$ Division of Infectious Diseases, University Hospital, Geneva, ${ }^{4}$ Division of Infectious Diseases, University Hospital, Bern, ${ }^{5}$ Infectious Diseases Practice, Lausanne, ${ }^{6}$ Division of Infectious Diseases, Cantonal Hospital, St. Gallen, ${ }^{7}$ Division of Infectious Diseases, Cantonal Hospital, Lugano, and ${ }^{8}$ Department of Medicine, University Hospital, Basel, Switzerland; ${ }^{9}$ Clinic of Infectious Diseases, San Raffaele Scientific Institute, Milan, Italy; ${ }^{10}$ GlaxoSmithKline, Greenford, United Kingdom
\end{abstract}

\begin{abstract}
This randomized study evaluated the efficacy and tolerability of continued treatment with protease inhibitor plus nucleoside-analogue combination regimens $(n=79)$ or a change to the simplified regimen of abacavir-lamivudine-zidovudine $(n=84)$ in patients with suppressed human immunodeficiency virus type 1 (HIV-1) RNA for $\geqslant 6$ months who did not have the reverse transcriptase 215 mutation. After a median follow-up of 84 weeks, virologic failure was $6 \%$ in the continuation and $15 \%$ in the simplified group $(P=\mathbf{. 0 8 1})$. Previous zidovudine monotherapy or dual therapy and archived reverse transcriptase resistance mutations in HIV-1 DNA at baseline were significant predictors of failure. Study treatment was discontinued because of adverse events in $20 \%$ of the continuation and $7 \%$ of the simplified group $(P=.021)$. Simplification to abacavir-lamivudine-zidovudine significantly decreased nonfasting cholesterol and triglyceride levels; however, this switch strategy carries a risk of virologic failure when treatment history or resistance testing suggest the presence of archived resistance mutations to the simplified regimen.
\end{abstract}

High pill burden, food and fluid requirements, and side effects are major constraints for human immunodeficiency virus (HIV)-infected patients undergoing protease inhibitor (PI)containing combination therapy. Although treatment simplification could help patients to maintain adherence-an important determinant of treatment success $[1,2]$ — continued virologic suppression must be ensured. Induction and maintenance strategies have been studied previously to determine their effectiveness in maintaining virologic suppression. After triple induction treatment for 3-6 months, $22 \%-31 \%$ of patients with virological suppression who reduced their therapy to lamivudine-zidovudine, lamivudine-indinavir, or indinavir alone experienced

Received 17 August 2001; revised 11 December 2001; electronically published 1 April 2002.

Presented in part: 40th Interscience Conference on Antimicrobial Agents and Chemotherapy, Toronto, 17-20 September 2000 (abstract 476).

The study protocol was approved by all local ethics committees, and all patients gave written informed consent.

Financial support: Swiss HIV Cohort Study (grant 202); Swiss National Science Foundation (grants 316.97 .7327 and 3345-062041); GlaxoWellcome provided pharmaceutical support for this study.

a Study group members are listed after the text.

Reprints or correspondence: Dr. Milos Opravil, University Hospital, Div. of Infectious Diseases and Hospital Epidemiology, CH-8091 Zurich, Switzerland (Milos.Opravil@dim.usz.ch).

The Journal of Infectious Diseases 2002;185:1251-60 (C) 2002 by the Infectious Diseases Society of America. All rights reserved. 0022-1899/2002/18509-0006\$02.00 rapid virologic rebound $[3,4]$. Similarly, reduction to 2 drugs after quadruple induction treatment failed to maintain virus suppression [5]. Zidovudine resistance at baseline, poor adherence, and low plasma levels of indinavir during maintenance therapy predicted virologic failure $[3,6,7]$. Thus, an optimal maintenance regimen must be potent but also easy to take.

We recruited patients being treated with PI-containing combination regimens who experienced virological suppression for $\geqslant 6$ months. On the basis of the assumption of similar antiviral potency, patients were randomized either to continue their current therapy or to change to abacavir-lamivudine-zidovudine. The main objective of the study was to determine the treatment efficacy of this regimen, which is simplified in terms of fewer pills and simpler dosing requirements. Additionally, we hypothesized that a switch from PI-containing therapy to 3 nucleoside-analogue reverse-transcriptase inhibitors (NRTIs) may have a beneficial effect on lipid abnormalities associated with PIs [8-10].

\section{Patients and Methods}

Study participants. We recruited from our outpatient clinics HIV-1-infected patients $\geqslant 18$ years old whose plasma virus levels had been $<400$ HIV-1 RNA copies/mL (Roche Amplicor HIV-1 Monitor assay, version 1.0) for $\geqslant 6$ months as a result of stable PI and NRTI combination therapy. None of the patients had ever received nonnucleoside reverse-transcriptase inhibitors (NNRTIs), either by prescription (this drug class was not available before the 
recruitment time) or in a trial. At screening, the plasma HIV-1 RNA level had to be $<50$ copies/mL (Roche Amplicor HIV-1 Ultrasensitive Monitor assay, version 1.5). Exclusion criteria were previous administration of abacavir, known previous failure of treatment with lamivudine and zidovudine given simultaneously, and abnormalities in hematology (hemoglobin level $<10 \mathrm{~g} / \mathrm{dL}$ for men or $<9$ $\mathrm{g} / \mathrm{dL}$ for women, neutrophil count $<1000$ cells $/ \mathrm{mm}^{3}$, or platelet count $<75,000$ cells $/ \mathrm{mm}^{3}$ ) or blood chemistry (alanine aminotransferase level $>5$ times the upper limit of normal or amylase level $>1.5$ times the upper limit of normal). On the basis of preliminary results of the AIDS Clinical Trials Group protocol 343 [3], patients were also excluded if an archived reverse transcriptase mutation at codon 215 was detected in their proviral DNA at screening or in the plasma RNA-derived sequence from the most recently stored sample with an HIV-1 RNA level of $\geqslant 1000$ copies $/ \mathrm{mL}$ for those without recoverable proviral DNA. Amplification and sequencing were done as described elsewhere $[11,12]$. Proviral DNA was subjected to nested polymerase chain reaction, to analyze codons $130-228$ of the reverse transcriptase gene; only mutations at codons 184,215 , and 219 were reported. Patients without amplifiable proviral DNA and without stored frozen plasma were allowed to enter the trial.

Study design. This was a prospective, randomized, controlled, open-label study conducted in 8 HIV outpatient clinics in Switzerland and Milan, Italy. Randomization was done by central fax, with use of a computerized schedule with randomly permutated block sizes of 2 and 4, stratified by center and by prior duration of undetectable plasma HIV-1 RNA ( $\leqslant 9$ or $>9$ months). Patients either continued their current regimen (continuation group) or switched to abacavir (300 mg) plus a lamivudine-zidovudine (150/300 mg) combination tablet (Combivir), each twice daily (simplified group). In February 2000, the simplified regimen was modified to consist of only 1 triple-combination tablet twice daily (Trizivir; abacavirlamivudine-zidovudine [300/150/300 mg]). Change in therapy was not permitted, except in case of treatment-limiting toxicity and only after approval by the study headquarters. These patients remained in the study, as did those who received a new regimen because of virologic failure.

Assessments and study end points. Study visits were every 4 weeks until week 48 and every 6 weeks thereafter until the last recruited patient completed 48 weeks of follow-up. Waist and hip circumference were measured every 12 weeks. Plasma HIV-1 RNA was measured every 4 weeks until week 24 and every 12 weeks thereafter. $\mathrm{CD}^{+}{ }^{+}$and $\mathrm{CD} 8^{+} \mathrm{T}$ cell numbers were determined every 12 weeks by use of a whole blood preparation method (Coulter) and 3-color flow cytometry [13]. In all Swiss centers, coexpression of CD38 and HLA-DR activation markers on $\mathrm{CD}^{+} \mathrm{T}$ cells was also measured. Optional tonsil biopsies were done for 23 patients from 2 centers after 1 year of randomized treatment. Virus loads in tonsil biopsy samples and in peripheral blood mononuclear cells (PBMC) of these patients were measured as reported elsewhere [14-16]. For patients with virologic failure, frozen PBMC from day 0 and plasma from the time of failure (first and confirmatory blood draw) were retrospectively retrieved, and the full sequence of the reverse transcriptase gene was analyzed. In patients with failure of continuation therapy, the protease gene was also sequenced.

The primary end point of the study was the number of patients with virologic failure, defined as a plasma HIV-1 RNA level of
$>400$ copies $/ \mathrm{mL}$ in 2 consecutive samples. Additional end points were treatment failure (defined as virologic failure, any change of randomized therapy, or loss to follow-up), tolerability, metabolic parameters, including nonfasting blood lipid measurements, and the development of resistance.

Statistical analysis. On the basis of results of previous trials [3, 4], the study was powered to detect a higher rate of virologic failure in the simplified group. Assuming a 5\% significance level and power of $80 \%, 156$ patients (78 per arm) were required to detect a failure rate of $10 \%$ and $25 \%$ in the continuation and simplified groups, respectively. The protocol included an interim analysis after the first 40 participants in the simplified group reached week 16 . The study would have been discontinued if the virologic failure rate had been $\geqslant 25 \%$.

The primary comparison was done on the intent-to-treat population fulfilling all of the inclusion criteria and having taken at least 1 dose of randomized treatment. Results of changes from baseline in laboratory values are expressed as medians with interquartile ranges. To compare groups, Fisher's exact test (for categorical variables) or the Mann-Whitney $U$ test was used (GraphPad Prism, version 3.00 for Windows; GraphPad). Stata software (version 7.0; StataCorp) was used for Cox proportional hazards regression analysis. The final model of the multivariable Cox regression analysis was chosen by a stepwise backward selection procedure.

\section{Results}

Patients. Patients were recruited between January 1998 and May 1999, with last follow-up in October 2000. Overall, 172 patients were randomized (figure 1). After exclusion of 3 patients who did not come for the day 0 visit and 6 with a protocol violation ( 1 patient with virus suppression of $<6$ months and 5 patients for whom the finding of a plasma RNA mutation at codon 215 was received only after their randomization), 79 patients in the continuation and 84 in the simplified group were evaluable for the primary trial comparison. Baseline characteristics were comparable, although slightly more patients in the continuation group had previously taken zidovudine monotherapy or dual therapy ( $48 \%$ vs. $37 \% ; P=.16$; table 1$)$. At the time of randomization, antiretroviral therapy included stavudine for $46 \%$ of patients in the continuation group versus $39 \%$ of patients in the simplified group and zidovudine for $54 \%$ in the continuation versus $61 \%$ in the simplified group. None of the patients had received abacavir before beginning the study. The PI taken by patients in the continuation group was indinavir for $52 \%$, nelfinavir for $20 \%$, ritonavir for $14 \%$, saquinavir for $3 \%$, and saquinavir plus ritonavir for $11 \%$.

Results of genotypic resistance testing at screening were available for 150 (92\%) of 163 patients, 131 from HIV-1 DNA from PBMC and 19 from HIV-1 RNA from previously stored plasma. For 2 patients, nucleic acid was not amplifiable from either PBMC or plasma, and, for 11 patients without amplifiable HIV-1 DNA from PBMC, no frozen plasma from a previous time with detectable viremia was available (figure 1). Resistance mutations at codon 184 or 219 were slightly more frequent at baseline in the 


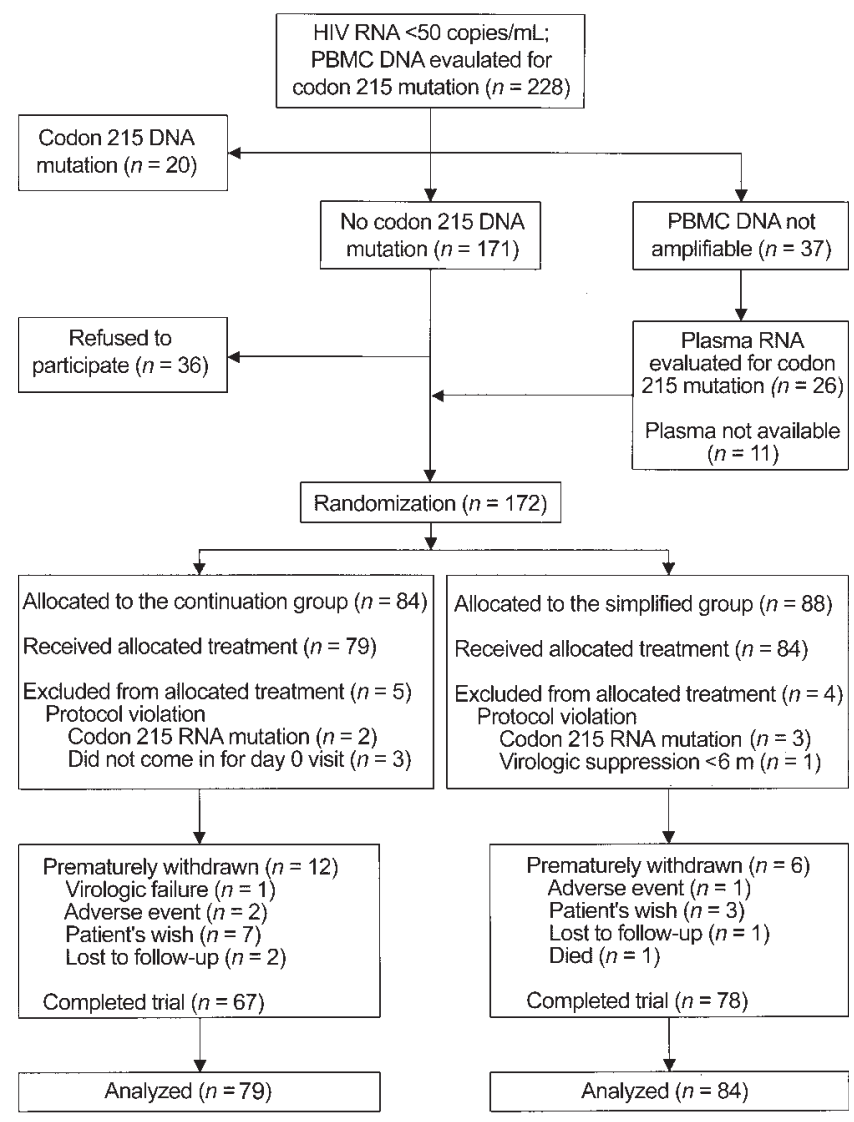

Figure 1. Profile of randomized trial of simplified maintenance therapy with abacavir, lamivudine, and zidovudine in human immunodeficiency virus-infected patients. PBMC, peripheral blood mononuclear cells.

continuation group (13 [19\%] of 70 vs. 8 [10\%] of $80 ; P=.16$; table 1).

Median study duration was 84 weeks, totaling 268 patientyears of observation. Twelve patients $(15.2 \%)$ in the continuation and $6(7.1 \%)$ in the simplified group discontinued the study prematurely or were lost to follow-up (table 2).

Virologic and treatment failure. In the intent-to-treat analysis of the overall population, virologic failure was more frequent in the simplified than in the continuation group, with 13 patients $(15 \%)$ versus 5 patients $(6.0 \%)$ experiencing treatment failure $(P=.081$, Fisher's exact test; table 2$)$. Time to virologic failure was also shorter in the simplified group $(P=.066, \log$ rank test; figure 2, middle). Virologic failure during randomized therapy occurred more frequently in the simplified than in the continuation group: $12(14 \%)$ versus 2 patients $(2.5 \% ; P=.01$, Fisher's exact test).

Time to treatment failure was similar between groups $(P=.46$, $\log$ rank test; figure 2, top ). In the intent-to-treat analysis, 25 patients $(32 \%)$ in the continuation group, compared with $22(26 \%)$ in the simplified group, experienced treatment failure (table 2).
Adverse events were more frequently the reason for treatment failure in the continuation group (16 vs. 6 patients; $P=.021$ ). Reasons for treatment change because of adverse events in the continuation versus the simplified group were gastrointestinal intolerance (6 vs. 1), new occurrence or worsening of lipodystrophy (6 vs. 0 ), hyperlipidemia ( 1 vs. 0$)$, nephrolithiasis ( 1 vs. 0$)$, abacavir hypersensitivity ( 0 vs. 1$)$, anemia or leukopenia ( 0 vs. 2 ), and other (2 vs. 2).

Characterization of virologic failures. Most of the virologic failures in the simplified group (8 [62\%] of 13) occurred before week 20 , whereas failures in the continuation group occurred between week 21 and 49 (table 3). At the time of virologic failure, the physician's opinion for the reason for virologic failure was poor adherence in 5 of 13 patients in the simplified and in 1 of 5

Table 1. Demographic data at time of randomization of human immunodeficiency virus (HIV)-infected patients to continuation therapy with protease inhibitor plus nucleoside-analogue combination regimen or simplified regimen of abacavir-lamivudine-zidovudine.

\begin{tabular}{|c|c|c|}
\hline Factor & $\begin{array}{l}\text { Continuation } \\
\text { group }(n=79)\end{array}$ & $\begin{array}{c}\text { Simplified } \\
\text { group }(n=84)\end{array}$ \\
\hline Male & $60(76)$ & $66(79)$ \\
\hline \multicolumn{3}{|l|}{ HIV risk factor } \\
\hline Homosexual activity & $40(51)$ & $43(51)$ \\
\hline Heterosexual activity & $18(23)$ & $18(21)$ \\
\hline Injection drug use & $20(25)$ & $21(25)$ \\
\hline Blood products or undetermined & $1(1)$ & $2(2)$ \\
\hline \multicolumn{3}{|l|}{ CDC disease stage } \\
\hline A & $47(59)$ & $51(61)$ \\
\hline B & $18(23)$ & $17(20)$ \\
\hline $\mathrm{C}$ & $14(18)$ & $16(19)$ \\
\hline Age, median years (range) & $41(27-65)$ & $38(23-66)$ \\
\hline $\begin{array}{l}\text { Duration of suppressed HIV-1 RNA, } \\
\text { median months (range) }\end{array}$ & $15(6-30)$ & $14(7-27)$ \\
\hline \multicolumn{3}{|l|}{$\begin{array}{l}\text { Duration of prior therapy, } \\
\text { median months (range) }\end{array}$} \\
\hline Antiretroviral therapy & $27(11-106)$ & $21(10-82)$ \\
\hline PI-containing antiretroviral therapy & $20(11-38)$ & $18(10-54)$ \\
\hline \multicolumn{3}{|l|}{ NRTI before start of PI therapy } \\
\hline Any NRTI & $40(51)$ & $35(42)$ \\
\hline Including zidovudine & $38(48)$ & $31(37)$ \\
\hline $\begin{array}{l}\text { Including lamivudine } \\
\text { (with prior zidovudine) }\end{array}$ & $14(18)$ & $13(15)$ \\
\hline \multicolumn{3}{|l|}{ Genotypic resistance } \\
\hline Result available & $70(89)$ & $80(95)$ \\
\hline Mutation at codon 184 & $10 / 70(14.3)$ & $6 / 80(7.5)$ \\
\hline Mutation at codon $219^{\mathrm{a}}$ & $4 / 70(5.7)$ & $2 / 80(2.5)$ \\
\hline $\begin{array}{l}\mathrm{CD} 4^{+} \text {lymphocyte count, } \\
\text { median cells } / \mathrm{mm}^{3}(\mathrm{IQR})\end{array}$ & $513(377-645)$ & $512(348-778)$ \\
\hline $\begin{array}{l}\mathrm{CD} 8^{+} \text {lymphocyte count, } \\
\text { median cells } / \mathrm{mm}^{3}(\mathrm{IQR})\end{array}$ & $907(673-1201)$ & $854(680-1067)$ \\
\hline Cholesterol, median mg/dL (IQR) ${ }^{\mathrm{b}}$ & $214(181-251)$ & $220(195-255)$ \\
\hline Triglycerides, median mg/dL (IQR) ${ }^{\mathrm{b}}$ & $157(113-279)$ & $187(134-283)$ \\
\hline
\end{tabular}

NOTE. Data are no. (\%) of patients, unless specified otherwise. Baseline parameters did not differ significantly between groups. IQR, interquartile range; PI, protease inhibitor; NRTI, nucleoside-analogue reverse-transcriptase inhibitor.

${ }^{\text {a }}$ One patient in continuation group had both 184 and 219 codon mutations.

${ }^{\mathrm{b}}$ Nonfasted values. 
Table 2. Virologic and treatment failure among human immunodeficiency virus (HIV)-infected patients randomized to continuation therapy with protease inhibitor plus nucleoside-analogue combination regimen or simplified regimen of abacavir-lamivudine-zidovudine.

\begin{tabular}{|c|c|c|c|}
\hline Parameter & $\begin{array}{l}\text { Continuation group } \\
\quad(n=79)\end{array}$ & $\begin{array}{l}\text { Simplified group } \\
\quad(n=84)\end{array}$ & $P$ \\
\hline \multicolumn{4}{|l|}{ Duration of follow-up } \\
\hline Median weeks & 83 & 85 & \\
\hline Total patient-years & 126 & 142 & \\
\hline No. (\%) with virologic failure, ITT ${ }^{\mathrm{a}}$ & $5(6)$ & $13(15)$ & .081 \\
\hline History of Zdv mono- or dual therapy & $4 / 38(10.5)$ & $9 / 31(29.0)$ & \\
\hline No prior Zdv mono- or dual therapy & $1 / 41(2.4)$ & $4 / 53(7.5)$ & \\
\hline No. $(\%)$ with treatment failure, ITT & $25(32)$ & $22(26)$ & .49 \\
\hline Premature end of randomized therapy ${ }^{\mathrm{b}}$ & 23 & 9 & .005 \\
\hline Changed $\geqslant 1$ drug because of adverse event & 16 & 6 & .021 \\
\hline Discontinued/lost to follow-up & 12 & 5 & NA \\
\hline Death $^{\mathrm{c}}$ & 0 & 1 & NA \\
\hline Virologic failure during randomized therapy & 2 & 12 & .01 \\
\hline Virologic failure on day 0 (before switch) & 0 & 1 & \\
\hline
\end{tabular}

NOTE. $P$ values are derived from Fisher's exact test. ITT, intent-to-treat, including those who switched treatment; NA, not applicable; Zdv, zidovudine.

${ }^{\text {a }}$ Stratification based on history of Zdv mono- or dual-nucleoside analogue therapy.

${ }^{\mathrm{b}}$ Subcategories of reasons for premature end of randomized therapy are not mutually exclusive (8 patients withdrew subsequent to change in therapy).

${ }^{\mathrm{c}}$ Non-Hodgkin's lymphoma.

patients in the continuation group, whereas the remaining cases were deemed to represent insufficient treatment potency. Seven of 13 patients who experienced virologic failure while taking the simplified regimen received a new regimen including a PI. Six, who also changed at least 1 NRTI, had subsequent plasma HIV-1 RNA level of $<50-80$ copies/mL during follow-up of $32-48$ weeks ( 1 of the centers used the threshold of 80 copies/ $\mathrm{mL}$ for follow-up measurements). One patient, whose only change was replacement of abacavir with nelfinavir, failed to respond. Five patients chose to continue the simplified regimen and had viremia always $<4000 \mathrm{HIV}-1$ RNA copies/mL during further follow-up. One patient with treatment failure on day 0 experienced full virologic suppression after switch to the simplified regimen. Of the 5 patients in the continuation group with treatment failure, 2 stopped all treatment and 3 chose salvage regimens, resulting in HIV-1 RNA levels of $<50,478$, and 140,000 copies/ $\mathrm{mL}$ after a median treatment duration of 16 weeks.

Genotypic analyses of the patients with virologic failure are summarized in table 3. In most patients with virologic failure, a wide range of resistance-conferring reverse transcriptase mutations was detected at the time of failure. However, several of these mutations, particularly among the simplified group, were already detected at baseline when proviral DNA from PBMC was analyzed retrospectively. These data indicate that, after switch to abacavir-lamivudine-zidovudine, reemergence of archived resistant virus may be a more important reason for virologic failure than development of new resistance mutations during simplified therapy.

History of previous mono- or dual zidovudine therapy was noted in most patients with virologic failure and was a predictor for virologic failure in the simplified group (9/31 patients with vs. 4/53 without prior zidovudine; odds ratio, 5.01; $95 \%$ confidence interval $[\mathrm{CI}], 1.39-18.0 ; P=.013$, Fisher's exact test) and in the entire patient population (13/69 with vs. 5/94 without prior zidovudine; odds ratio, $4.13 ; 95 \% \mathrm{CI}, 1.40-12.2 ; P=$ .010). When patients were stratified by history of mono- or dual zidovudine therapy, the risk of virologic failure among the 31 patients in the simplified group who had a history of zidovudine treatment was $23.5 \%$ after 48 weeks and $33.3 \%$ after 96 weeks; however, the risk of virologic failure was $<6 \%$ after 48 weeks and $<11 \%$ after 96 weeks for those without prior zidovudine mono- or dual therapy, independently of simplification (KaplanMeier analysis; figure 2, bottom). In a multivariable Cox regression analysis for all 150 patients with available results from baseline resistance testing, previous zidovudine mono- or dual therapy (hazard ratio, 3.78; 95\% CI, 1.13-12.6; $P=.030$ ), resistance mutation in codon 184 or 219 of the reverse transcriptase at baseline (hazard ratio, 4.23; 95\% CI, 1.17-15.3; $P=$ .028 ), and higher $\mathrm{CD}^{+}$lymphocyte count at randomization (hazard ratio, 1.14/100-cell increase; 95\% CI, 1.001-1.29; $P=.048$ ) were predictive of subsequent virologic failure (table 4).

Lymphocyte subpopulations and virus load in cellular compartments. $\quad \mathrm{CD}^{+} \mathrm{T}$ cells continued to increase throughout the study, with little difference between the groups (figure 3). CD8 ${ }^{+}$ $\mathrm{T}$ cell numbers remained unchanged over time in both groups; the median changes at week 48 from baseline were +52 cells/ $\mathrm{mm}^{3}$ (interquartile range, -73 to +205 cells $/ \mathrm{mm}^{3}$ ) and +58 cells $/ \mathrm{mm}^{3}$ (interquartile range, -50 to +122 cells $/ \mathrm{mm}^{3}$ ) in the continuation and simplified groups. In the subset of 130 patients from the Swiss centers, $\mathrm{CD} 8^{+} \mathrm{T}$ cells were further examined for 


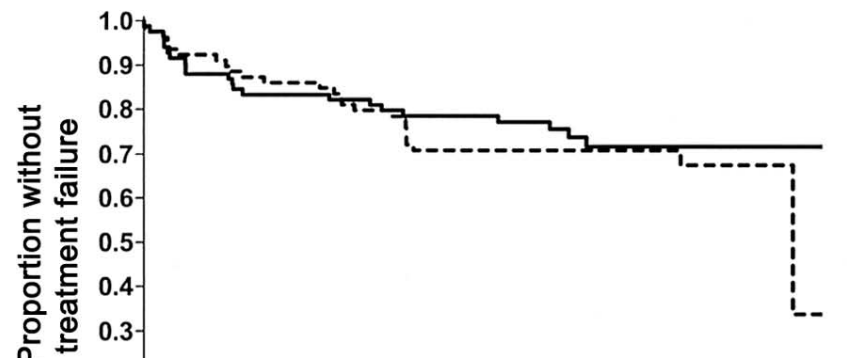

$0.2-$

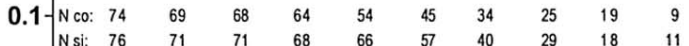

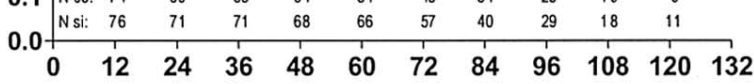
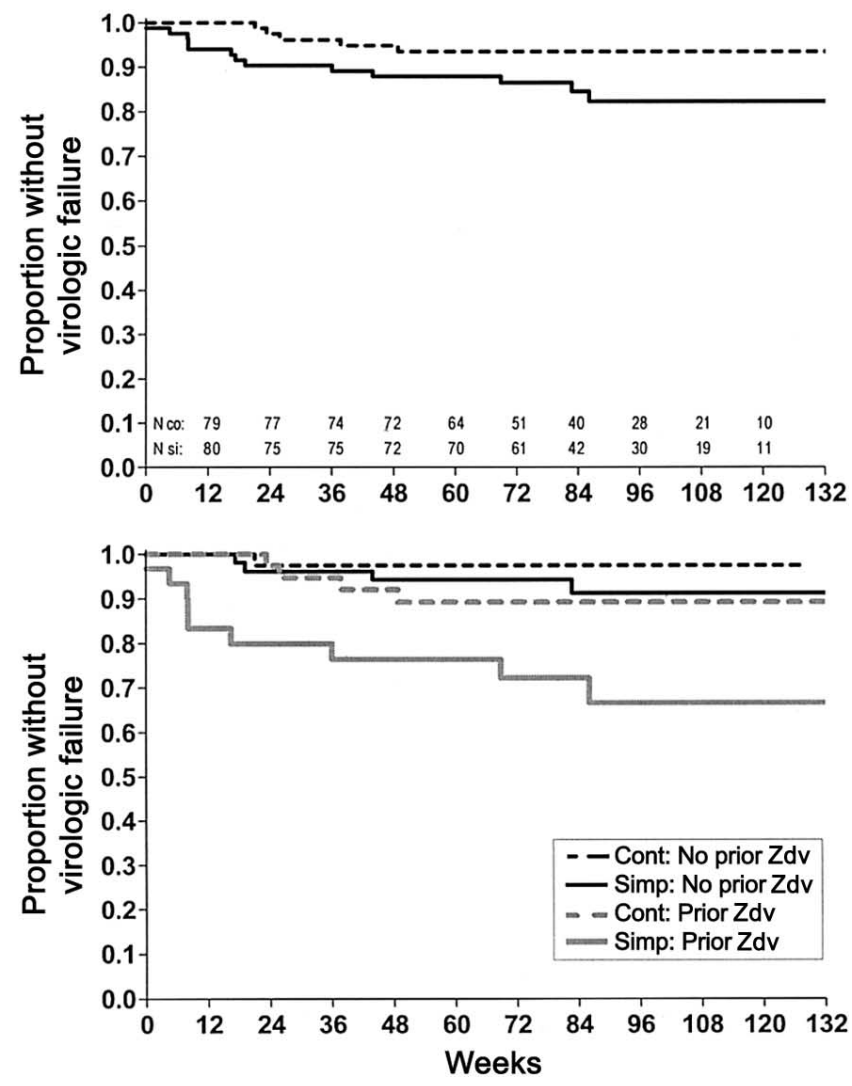

Figure 2. Probability of treatment failure (top; $P=.46, \log$ rank test) and of virologic failure (middle; $P=.066, \log$ rank test) in human immunodeficiency virus-infected patients receiving continuation (cont; dashed line) or simplified (simp; solid line) therapy. "N co" and "N si" are nos. of subjects in continuation and simplified groups, respectively, at each time point. Bottom, Probability of virologic failure after patients were stratified by history of previous zidovudine ( $\mathrm{Zdv}$ ) mono- or dual therapy (solid lines, no prior $\mathrm{Zdv}$ mono- or dualnucleoside therapy; shaded lines, history of prior Zdv mono- or dualnucleoside therapy).

CD38 and HLA-DR activation markers. $\mathrm{CD}^{+} \mathrm{T}$ cells were predominantly negative for both CD38 and HLA-DR activation markers throughout the study in both groups. CD $38^{+}$HLA-DR ${ }^{+}$ $\mathrm{CD}^{+} \mathrm{T}$ cell numbers, assessed as a possible marker of persis- tent low-level viral replication, remained low, with medians of 23 cells $/ \mathrm{mm}^{3}$ at week 0 and at week 48 in the continuation group and medians of 20 cells $/ \mathrm{mm}^{3}$ at week 0 and 17 cells $/ \mathrm{mm}^{3}$ at week 48 in the simplified group.

Nine patients in the continuation and 14 in the simplified group, all of whom were receiving their randomized treatment and had plasma HIV-1 RNA levels suppressed to $<50$ copies/mL between week 24 and 48, consented to have tonsil biopsies done after 1 year of study treatment. At this time point, virus load in tonsils did not differ between groups: the mean ( \pm SD) HIV-1 RNA load was $0.667 \pm 0.655 \log _{10}$ copies/ $\mu \mathrm{g}$ of total RNA in the continuation group versus $0.538 \pm 0.572 \log _{10}$ copies/ $\mu \mathrm{g}$ of total RNA in the simplified group, and the mean HIV-1 DNA load was $2.511 \pm 0.547 \log _{10}$ proviral copies $/ 10^{6}$ cells in the continuation group versus $2.468 \pm 0.300 \log _{10}$ proviral copies $/ 10^{6}$ cells in the simplified group. HIV-1 RNA and DNA were also measured in PBMC from these patients at weeks 0, 48, and 96. The mean values ranged from 0.89 to $1.37 \log _{10}$ copies/ $\mu \mathrm{g}$ of total RNA for HIV-1 RNA and from 2.1 to $2.4 \log _{10}$ proviral copies $/ 10^{6}$ cells for HIV-1 DNA, with no significant difference either between the groups or between the 3 time points.

Metabolic outcomes. In the simplified group, nonfasting serum cholesterol levels decreased from baseline by a median of $35 \mathrm{mg} / \mathrm{dL}$ at week 4 and remained reduced thereafter (figure 4). The changes from baseline differed between the 2 groups at all time points $(P<.002)$. Because high-density lipoprotein cholesterol remained unchanged in both groups, the reduction in total cholesterol in the simplified group was the effect of decreased non-high-density lipoprotein fractions. There was also a significant difference in the change from baseline in nonfasting triglyceride levels, with a reduction by $43 \mathrm{mg} / \mathrm{dL}$ at week 48 in the simplified group. Only 10 and 3 patients in the continuation and simplified groups, respectively, received lipid-lowering drugs during the study. Weight and waist-to-hip ratio did not change throughout the study in either group (data not shown).

Clinical events. During the course of the study, 2 patients in each group developed new HIV-associated illnesses: synovial mycobacteriosis and oral thrush in the continuation group and cryptosporidiosis and 1 death due to non-Hodgkin's lymphoma in the simplified group.

Overall, 65 treatment-related adverse events occurred in 34 patients in the continuation group and 66 occurred in 38 patients in the simplified group. However, discontinuation of randomized treatment due to adverse events was more frequent in the continuation group (see above), mainly because of gastrointestinal intolerance and lipodystrophy. Five serious treatment-related adverse events were reported: 1 myocardial infarction, 1 nephrolithiasis attributed to indinavir, and 1 unilateral gynecomastia (requiring surgical excision) in the continuation group and 1 abacavir hypersensitivity with rash and fever and 1 neutropenia in the simplified group. In addition, 1 myocardial infarction that was not considered treatment-related occurred in the simplified group. 
Table 3. Resistance testing in patients with virologic failure (intent-to-treat analysis) in study of continuation therapy with protease inhibitor plus nucleoside-analogue combination regimen or simplified regimen of abacavir-lamivudine-zidovudine.

\begin{tabular}{|c|c|c|c|c|}
\hline $\begin{array}{l}\text { Group, study } \\
\text { week at which } \\
\text { failure occurred }\end{array}$ & Adherence $^{\mathrm{a}}$ & $\begin{array}{l}\text { Prior zidovudine } \\
\text { without PI, } \\
\text { weeks }\end{array}$ & $\begin{array}{c}\text { Mutations in RT (or RT } \\
\text { and Pr) DNA (PBMC) } \\
\text { at baseline }\end{array}$ & $\begin{array}{l}\text { Mutations in RT (or RT } \\
\text { and Pr) RNA (plasma) } \\
\text { at treatment failure }{ }^{\mathrm{b}}\end{array}$ \\
\hline \multicolumn{5}{|l|}{ Simplified } \\
\hline 0 & Poor & 27 & None & $184 \mathrm{~V}$ \\
\hline 5 & Good & 43 & 41L,184I & $41 \mathrm{~L}, 184 \mathrm{~V}, 210 \mathrm{~W}, 215 \mathrm{Y}$ \\
\hline 8 & Good & 17 & None & $41 \mathrm{~L}, 184 \mathrm{~V}, 215 \mathrm{Y}$ \\
\hline 8 & Good & 38 & None & $41 \mathrm{~L}, 67 \mathrm{~N}, 70 \mathrm{R}, 215 \mathrm{~F}, 219$ \\
\hline 8 & Good & 165 & $67 \mathrm{~N}, 70 \mathrm{R}$ & $67 \mathrm{~N}, 70 \mathrm{R}, 184 \mathrm{~V}, 215 \mathrm{~F}, 219 \mathrm{Q}$ \\
\hline 16 & Good & 75 & None & $41 \mathrm{~L}, 184 \mathrm{~V}, 215 \mathrm{Y}$ \\
\hline 17 & Good & 0 & $67 \mathrm{~N}, 70 \mathrm{R}, 184 \mathrm{~V}$ & $67 \mathrm{~N}, 69 \mathrm{D}, 70 \mathrm{R}, 184 \mathrm{~V}$ \\
\hline 19 & Poor & 0 & None & No amplification \\
\hline 36 & Good & 44 & None & $41 \mathrm{~L}, 67 \mathrm{~N}, 184 \mathrm{~V}, 210 \mathrm{~W}, 215 \mathrm{Y}$ \\
\hline 44 & Poor & 0 & $70 \mathrm{~K} / \mathrm{R}$ & $67 \mathrm{~N}, 69 \mathrm{~N}, 70 \mathrm{R}, 184 \mathrm{M} / \mathrm{V}, 215 \mathrm{~F}, 219 \mathrm{Q}$ \\
\hline 69 & Poor & 178 & $67 \mathrm{D} / \mathrm{N}, 215 \mathrm{~T} / \mathrm{F}, 219 \mathrm{~K} / \mathrm{E}$ & $67 \mathrm{~N}, 70 \mathrm{R}, 181 \mathrm{Y} / \mathrm{C}, 184 \mathrm{~V}, 215 \mathrm{~F}, 219 \mathrm{E}$ \\
\hline 83 & Good & 0 & None & $184 \mathrm{~V}$ \\
\hline 86 & Poor & 17 & $184 \mathrm{~V}$ & $41 \mathrm{~L}, 184 \mathrm{~V}, 215 \mathrm{Y}$ \\
\hline \multicolumn{5}{|l|}{ Continuation } \\
\hline 21 & Poor & 0 & $\begin{array}{l}\text { RT; no amplification } \\
\text { Pr; ND at baseline }\end{array}$ & $\begin{array}{l}\text { None } \\
63 \mathrm{C}, 77 \mathrm{I}\end{array}$ \\
\hline 23 & Good & 9 & $\begin{array}{l}\text { RT; } 215 T / F \\
\text { Pr; 63P }\end{array}$ & $\begin{array}{l}\text { None } \\
48 \mathrm{~V}, 54 \mathrm{~V} / \mathrm{I}, 63 \mathrm{P}, 82 \mathrm{~A}\end{array}$ \\
\hline 26 & Good & 164 & $\begin{array}{l}\mathrm{RT} ; 70 \mathrm{~K} / \mathrm{R} \\
\mathrm{Pr} ; 33 \mathrm{~V}\end{array}$ & $\begin{array}{l}41 \mathrm{~L}, 67 \mathrm{~N}, 70 \mathrm{R}, 184 \mathrm{~V}, 215 \mathrm{~F}, 219 \mathrm{Q} \\
30 \mathrm{~N}, 33 \mathrm{~V}\end{array}$ \\
\hline 38 & Good & 96 & $\begin{array}{l}\text { RT; 70R } \\
\text { Pr; 20I,63S }\end{array}$ & $\begin{array}{l}67 \mathrm{~N}, 69 \mathrm{~S}, 70 \mathrm{R}, 184 \mathrm{~V}, 219 \mathrm{Q} \\
20 \mathrm{I}, 30 \mathrm{~N}, 33 \mathrm{~F}, 63 \mathrm{~S}, 77 \mathrm{I}, 88 \mathrm{D}\end{array}$ \\
\hline 49 & Good & 105 & $\begin{array}{l}\text { RT; none } \\
\text { Pr; ND at baseline }\end{array}$ & $\begin{array}{l}41 \mathrm{~L}, 184 \mathrm{~V}, 215 \mathrm{Y}, 219 \mathrm{Q} \\
63 \mathrm{P}\end{array}$ \\
\hline
\end{tabular}

NOTE. ND, not done; PBMC, peripheral blood mononuclear cells; PI, protease inhibitor.

${ }^{a}$ Physician's opinion for reason for virologic failure at time of virologic failure.

${ }^{\mathrm{b}}$ For simplified group, mutations sought were in reverse transcriptase (RT) DNA and RNA; for continuation group, mutations sought were in RT and protease (Pr) DNA and RNA.

\section{Discussion}

In this prospective, randomized trial, we tested the hypothesis that HIV-1-infected patients who have been virologically suppressed as a result of a PI- and NRTI-containing regimen may simplify their therapy by switching to the triple-NRTI combination of abacavir-lamivudine-zidovudine. In the overall population, virologic failure was more frequent $(15 \%$ vs. $6 \% ; P=$ $.081)$ and occurred faster in the simplified group $(P=.066, \log$ rank test). On the other hand, more patients in the continuation group changed treatment because of adverse events (20\% vs. $7 \% ; P=.021)$, leading to similar rates of overall treatment failure $(32 \%$ vs. $26 \% ; P=.49)$.

The virologic failure rate in the simplified group was at least partially driven by a high failure rate (9 [29\%] of 31) among patients with a history of zidovudine mono- or dual therapy. Although we performed genotypic resistance testing on HIV-1 DNA from PBMC at baseline and - on the basis of preliminary results of the ACTG 343 trial [3, 4] — excluded patients with the key zidovudine resistance mutation at codon 215 , patients with other mutations of the reverse transcriptase (e.g., codon 184 or 219) were able to enter the trial. Resistance mutations at codon 184 or 219 and history of prior zidovudine mono- or dual therapy were subsequently identified as significant predictors of virologic failure by multivariable Cox regression analysis. Baseline zidovudine resistance mutations have been previously reported to predict loss of virus suppression during maintenance therapy [3], and multiple zidovudine and lamivudine resistance mutations cause cross-resistance to abacavir [17]. This stresses the importance of carefully assessing previous treatment history in potential candidates for treatment simplification, because the genotypic assay may not detect mutations expressed at low level in the archived virus. The latter concept is indirectly supported by the high rate of virologic failure observed in patients with previous exposure to zidovudine even in the absence of a resistance mutation at baseline. Although the impact of treatment history with other NRTIs could not be assessed in this study because zidovudine was the agent predominantly administered in mono- or dual therapy, our data indicate that archived virus resistant to NRTIs can quickly become the dominant circulating virus population if the new regimen is not fully suppressive.

Virologic failure was $3.8 \%$ after 48 weeks in patients who replaced the PI with abacavir and continued their prior NRTIs in another trial; in that trial, only $9 \%$ of patients were NRTI-pretreated [18], compared with $46 \%$ in our population. Among the 
Table 4. Risk for loss of virus suppression (Cox regression analysis, stratified by center) among human immunodeficiency virus (HIV)-infected patients randomized to continuation therapy with protease inhibitor plus nucleoside-analogue combination regimen or simplified regimen of abacavir-lamivudine-zidovudine.

\begin{tabular}{|c|c|c|c|c|}
\hline \multirow[b]{2}{*}{ Variable } & \multicolumn{2}{|c|}{ Univariable } & \multicolumn{2}{|c|}{ Multivariable } \\
\hline & HR $(95 \% \mathrm{CI})$ & $P$ & HR $(95 \% \mathrm{CI})$ & $P$ \\
\hline Simplified vs. continuation arm & $2.51(0.89-7.09)$ & .082 & $3.65(1.15-11.6)$ & .029 \\
\hline Prior Zdv therapy without PI & $3.17(1.05-9.56)$ & .041 & $3.78(1.13-12.6)$ & .030 \\
\hline Genotypic resistance $^{\mathrm{a}}$ & $4.48(1.35-14.9)$ & .014 & $4.23(1.17-15.3)$ & .028 \\
\hline $\mathrm{CD}^{+}{ }^{+}$cell count at randomization ${ }^{\mathrm{b}}$ & $1.13(1.02-1.27)$ & .018 & $1.14(1.001-1.29)$ & .048 \\
\hline
\end{tabular}

NOTE. Univariable results are derived from all 163 patients, except for baseline genotypic resistance, which was available for 150 patients only. Multivariable results are derived from 150 patients. Probability of overall model: $P=.001$. CI, confidence interval; HR, hazard ratio; PI, protease inhibitor; Zdv, zidovudine.

${ }^{\mathrm{a}}$ Codon 184 or 219 resistance mutation at randomization.

${ }^{\mathrm{b}}$ Per $100-$ cells $/ \mathrm{mm}^{3}$ increase.

53 patients without prior zidovudine mono- or dual therapy in our study, the risk of virologic failure after changing to abacavir-lamivudine-zidovudine was $5.7 \%$ at 48 weeks and $8.7 \%$ at 96 weeks (Kaplan-Meier analysis). Therefore, the applied switch strategy seems to be virologically safe as long as prior treatment history and/or resistance testing suggest absence of resistance to the drugs administered in the new regimen. The adequate virologic potency of abacavir-lamivudine-zidovudine per se has been demonstrated in a comparative, double-blind trial in treatment-naive patients [19], a population likely to lack preexisting resistance mutations. Those patients in our trial who experienced treatment failure with abacavir-lamivudine-zidovudine had multiple resistance mutations to NRTIs, but a salvage regimen was usually successful because of preserved activity of other drug classes.

$\mathrm{CD}^{+}{ }^{+}$and activated $\mathrm{CD} 8^{+} \mathrm{T}$ cells, the latter known to be an independent marker of persistent viral replication and poor prognosis [20-22], showed a similar time course in both groups. Of note, even after a median of $\sim 2$ years of prior antiretroviral therapy, $\mathrm{CD}^{+} \mathrm{T}$ cell counts continued to increase in both groups during the study, supporting the concept of long-term immune recovery in patients with continuously suppressed viral replication [23, 24].

Previous studies suggest that, despite suppression of HIV-1 RNA in plasma, treatment with 2 NRTIs alone or NRTIs plus nevirapine is less potent than NRTIs plus PIs or efavirenz to suppress virus load in lymphoid tissue [25-27]. Therefore, we analyzed cell-associated virus load in tonsil biopsy samples after 1 year of study treatment and found no differences between patients receiving the triple-NRTI combination and those receiving PI-containing regimens. Cell-associated HIV-1 RNA in PBMC, which correlates with virus load in lymph nodes [28], was additionally determined for those patients who underwent tonsil biopsies and was similar between the groups, suggesting that the potency of this triple-NRTI regimen to suppress viral replication in cellular compartments is in the range of previously reported results from patients treated with PI-containing regimens [15, 29-31].

PI therapy is associated with hypertriglyceridemia and hypercholesterolemia [8-10]. In this study, patients in the sim- plified group experienced statistically significant reductions in nonfasting serum cholesterol and triglyceride concentrations, which may decrease the risk of long-term cardiovascular morbidity. The use of nonfasting blood samples partially limits the interpretation of the triglyceride levels; however, fasting and nonfasting triglycerides recently have been shown to correlate well in a group of $24 \mathrm{HIV}$-infected patients [32].

The number of treatment changes due to adverse events may be potentially biased because of the open-label nature of this study. Change of therapy, however, was permitted only in cases of severe or strongly disturbing toxicity after approval by the study headquarters. Moreover, abacavir was not available in Switzerland and Italy during most of the study duration, and patients from the continuation group were not allowed to receive the simplified medication. Therefore, the relatively high rate of treatment changes in the continuation group seems to primarily reflect long-term toxicity of PI and NRTI combination regimens.

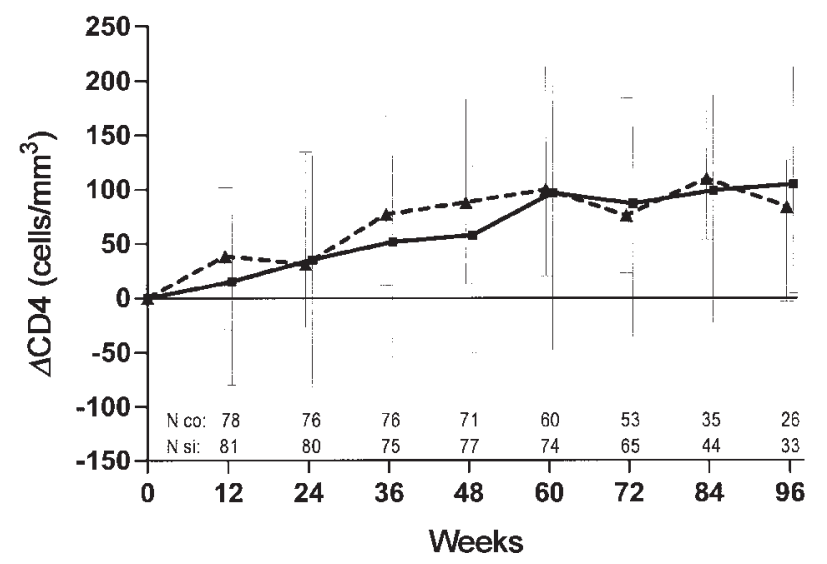

Figure 3. Changes from baseline $(\Delta)$ in $\mathrm{CD}^{+}$lymphocyte numbers, intent-to-treat analysis, of patients randomized to continuation therapy (dashed line) or simplified therapy (solid line). Symbols represent medians; bars represent interquartile ranges. " $\mathrm{N}$ co" and " $\mathrm{N}$ si" are nos. of subjects in continuation and simplified groups, respectively, at each time point. Changes from baseline did not differ significantly between arms. 

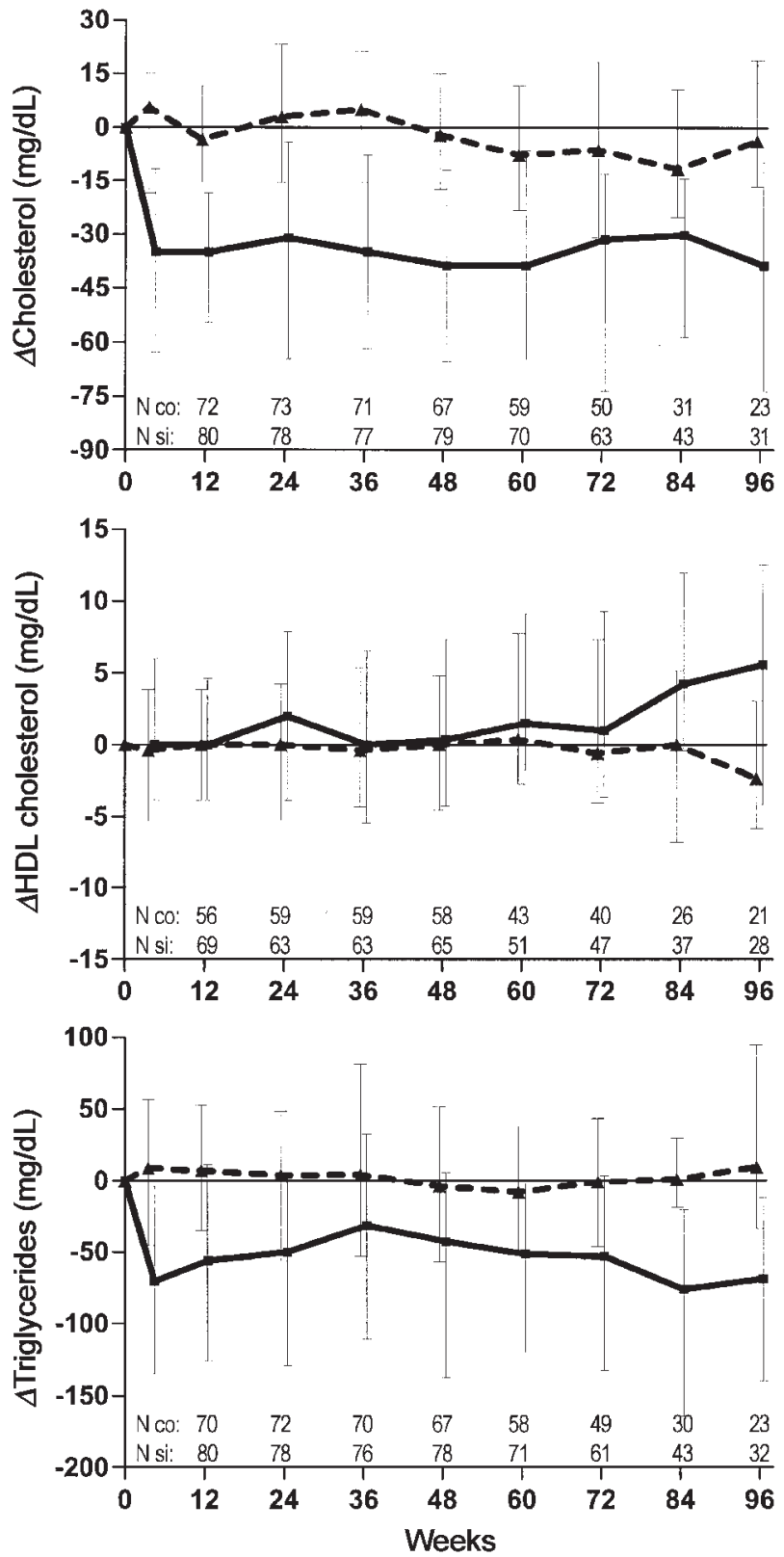

Figure 4. Changes from baseline $(\Delta)$ in levels of nonfasting cholesterol, high-density lipoprotein (HDL) cholesterol, and triglycerides, intent-to-treat analysis, in patients randomized to continuation therapy (dashed line) or simplified therapy (solid line). Symbols represent medians; bars represent interquartile ranges. "N co" and "N si" are nos. of subjects in continuation and simplified groups, respectively, at each time point. Groups differed regarding changes from baseline in cholesterol $(P<.002$ at all time points $)$ and triglyceride levels $(P \leqslant .005$ except for $P \leqslant .01$ at weeks 36 and 72) but not regarding changes in HDL cholesterol levels.

A high degree of adherence, ideally exceeding 90\%-95\%, has been shown to be required for optimal virus suppression [1]. On the basis of self-reported percentage of pills taken to pills prescribed during the time between study visits, the simplified group had a significantly lower frequency of study visits with adherence $<90 \%$ to any drug than did the continuation group (data not shown). Although such a measurement is subjective, the low number of daily pills and the good tolerability of the simplified regimen are important features of a long-term therapeutic strategy and may help to maintain antiviral efficacy. This is confirmed by additional randomized studies examining the switch from PIs to either abacavir or nevirapine, which have reported easier adherence and improved quality of life for patients who switched [18, 33].

This study is limited with regard to including only patients with PI but without NNRTI experience. In the population studied, changing to a triple-NRTI combination may not be the only simplification choice. Replacing PIs with nevirapine or efavirenz has been done with good virologic success [33-36]. However, pretreatment with NRTIs alone may also predispose to frequent virologic failure after switching from PIs to NNRTIs, demonstrated by failure rates ranging from $19 \%$ to $50 \%$ in patients with prior NRTI experience [37-39]. Thus far, effects on clinical lipodystrophy have not been conclusive with any switch strategy; if the abnormal fat distribution regresses at all, it may require several years.

In conclusion, treatment simplification from a PI-containing regimen in patients with good virus suppression resulted in better adherence, fewer adverse events leading to drug discontinuation, and a clinically meaningful reduction in blood lipids. However, the rate of virologic failure was increased among patients who changed to abacavir-lamivudine-zidovudine if they had previously received zidovudine or had evidence of resistance mutations. This strategy, therefore, is appropriate only for patients with no prior zidovudine mono- or dual therapy and no suggestion or evidence of resistance to NRTIs.

\section{Swiss HIV Cohort Study}

The members of the Swiss HIV Cohort Study are R. Amiet, M. Battegay (Chairman of the Scientific Board), E. Bernasconi, H. Bucher, P. Bürgisser, M. Egger, P. Erb, W. Fierz, M. Flepp (Chairman of the Clinical and Laboratory Committee), P. Francioli (President of the Swiss HIV Cohort Study, Centre Hospitalier Universitaire Vaudois, Lausanne), H. J. Furrer, M. Gorgievski, H. Günthard, P. Grob, B. Hirschel, C. Kind, T. Klimkait, B. Ledergerber, U. Lauper, M. Opravil, F. Paccaud, G. Pantaleo, L. Perrin, W. Pichler, J.-C. Piffaretti, M. Rickenbach (Head of Data Center), C. Rudin (Chairman of the Mother \& Child Substudy), P. Sudre, V. Schiffer, J. Schupbach, A. Telenti, P. Vernazza, and R. Weber.

\section{Acknowledgments}

We thank Christina Grube for patient care and data entry, Doris Baumann and Lorenzo Magenta for patient care, Peter Ott for performing the tonsil biopsies, Beda Joos for laboratory work, Shirley Kwok and Cindy Christopherson (Roche Molecular Systems) for 
providing kits for the proviral human immunodeficiency virus DNA assay, Philippe Sudre for statistical help, Christophe Python (GlaxoSmithKline) for administrative help, and Justin Cook for writing and editing assistance.

\section{References}

1. Paterson DL, Swindells S, Mohr J, et al. Adherence to protease inhibitor therapy and outcomes in patients with HIV infection. Ann Intern Med 2000; $133: 21-30$.

2. Gifford AL, Bormann JE, Shively MJ, Wright BC, Richman DD, Bozzette SA. Predictors of self-reported adherence and plasma HIV concentrations in patients on multidrug antiretroviral regimens. J Acquir Immune Defic Syndr 2000; 23:386-95.

3. Havlir DV, Marschner IC, Hirsch MS, et al. Maintenance antiretroviral therapies in HIV infected patients with undetectable plasma HIV RNA after triple-drug therapy. AIDS Clinical Trials Group Study 343 Team. N Engl J Med 1998; 339:1261-8.

4. Pialoux G, Raffi F, Brun VF, et al. A randomized trial of three maintenance regimens given after three months of induction therapy with zidovudine, lamivudine, and indinavir in previously untreated HIV-1-infected patients. Trilege (Agence Nationale de Recherches sur le SIDA 072) Study Team. N Engl J Med 1998; 339:1269-76.

5. Reijers MH, Weverling GJ, Jurriaans S, et al. Maintenance therapy after quadruple induction therapy in HIV-1 infected individuals: Amsterdam Duration of Antiretroviral Medication (ADAM) study. Lancet 1998; 352:185-90.

6. Havlir DV, Hellmann NS, Petropoulos CJ, et al. Drug susceptibility in HIV infection after viral rebound in patients receiving indinavir-containing regimens. JAMA 2000;283:229-34.

7. Descamps D, Flandre P, Calvez V, et al. Mechanisms of virologic failure in previously untreated HIV-infected patients from a trial of inductionmaintenance therapy. Trilege (Agence Nationale de Recherches sur le SIDA 072) Study Team. JAMA 2000;283:205-11.

8. Mulligan K, Grunfeld C, Tai VW, et al. Hyperlipidemia and insulin resistance are induced by protease inhibitors independent of changes in body composition in patients with HIV infection. J Acquir Immune Defic Syndr 2000; $23: 35-43$.

9. Tsiodras S, Mantzoros C, Hammer S, Samore M. Effects of protease inhibitors on hyperglycemia, hyperlipidemia, and lipodystrophy: a 5-year cohort study. Arch Intern Med 2000; 160:2050-6.

10. Bonnet F, Saves M, Droz C, et al. Increase of atherogenic plasma profile in HIV-infected patients treated with protease inhibitor-containing regimens. J Acquir Immune Defic Syndr 2000;25:199-200.

11. Yerly S, Kaiser L, Race E, Bru JP, Clavel F, Perrin L. Transmission of antiretroviral-drug-resistant HIV-1 variants. Lancet 1999; 354:729-33.

12. Yerly S, Perneger TV, Vora S, Hirschel B, Perrin L. Decay of cell-associated HIV-1 DNA correlates with residual replication in patients treated during acute HIV-1 infection. AIDS 2000; 14:2805-12.

13. Centers for Disease Control and Prevention. 1997 Revised guidelines for performing $\mathrm{CD}^{+}{ }^{+} \mathrm{T}$-cell determinations in persons infected with human immunodeficiency virus (HIV). MMWR Morb Mortal Wkly Rep 1997; 46:1-29.

14. Fischer M, Huber W, Kallivroussis A, et al. Highly sensitive methods for quantitation of human immunodeficiency virus type 1 RNA from plasma, cells, and tissues. J Clin Microbiol 1999;37:1260-4.

15. Fischer M, Gunthard HF, Opravil M, et al. Residual HIV-RNA levels persist for up to 2.5 years in peripheral blood mononuclear cells of patients on potent antiretroviral therapy. AIDS Res Hum Retroviruses 2000; 16 : 1135-40.

16. Christopherson C, Kidane Y, Conway B, Krowka J, Sheppard H, Kwok S. PCR-based assay to quantify human immunodeficiency virus type 1
DNA in peripheral blood mononuclear cells. J Clin Microbiol 2000; 38:630-4.

17. Tisdale M, Alnadaf T, Cousens D. Combination of mutations in human immunodeficiency virus type 1 reverse transcriptase required for resistance to the carbocyclic nucleoside 1592U89. Antimicrob Agents Chemother 1997; 41:1094-8.

18. Clumeck N, Goebel F, Rozenbaum W, et al. Simplification with abacavirbased triple nucleoside therapy versus continued protease inhibitorbased highly active antiretroviral therapy in HIV-1-infected patients with undetectable plasma HIV-1 RNA. AIDS 2001; 15:1517-26.

19. Staszewski S, Keiser P, Montaner J, et al. Abacavir-lamivudine-zidovudine vs. indinavir-lamivudine-zidovudine in antiretroviral-naive HIV-infected adults: a randomized equivalence trial. JAMA 2001;285: $1155-63$.

20. Liu Z, Cumberland WG, Hultin LE, Kaplan AH, Detels R, Giorgi JV. $\mathrm{CD}^{+} \mathrm{T}$-lymphocyte activation in HIV-1 disease reflects an aspect of pathogenesis distinct from viral burden and immunodeficiency. J Acquir Immune Defic Syndr Hum Retrovirol 1998; 18:332-40.

21. Bouscarat F, Levacher M, Landman R, et al. Changes in blood CD8 ${ }^{+}$lymphocyte activation status and plasma HIV RNA levels during antiretroviral therapy. AIDS 1998; 12:1267-73.

22. Burgisser P, Hammann C, Kaufmann D, Battegay M, Rutschmann OT. Expression of CD28 and CD38 by CD8 ${ }^{+} \mathrm{T}$ lymphocytes in HIV-1 infection correlates with markers of disease severity and changes towards normalization under treatment. The Swiss HIV Cohort Study. Clin Exp Immunol 1999; 115:458-63.

23. Notermans DW, Pakker NG, Hamann D, et al. Immune reconstitution after 2 years of successful potent antiretroviral therapy in previously untreated human immunodeficiency virus type 1-infected adults. J Infect Dis 1999; 180:1050-6.

24. Kaufman GR, Bloch M, Zaunders JJ, Smith D, Cooper DA. Long-term immunological response in HIV-1-infected subjects receiving potent antiretroviral therapy. AIDS 2000; 14:959-69.

25. Ruiz L, van Lunzen J, Arno A, et al. Protease inhibitor-containing regimens compared with nucleoside analogues alone in the suppression of persistent HIV-1 replication in lymphoid tissue. AIDS 1999;13:F1-8.

26. Martinez E, Arnedo M, Giner V, et al. Lymphoid tissue viral burden and duration of viral suppression in plasma. AIDS 2001; 15:1477-82.

27. Dybul M, Chun TW, Ward DJ, et al. Evaluation of lymph node virus burden in human immunodeficiency virus-infected patients receiving efavirenz-based protease inhibitor-sparing highly active antiretroviral therapy. J Infect Dis 2000; 181:1273-9.

28. Yerly S, Rutschmann OT, Opravil M, et al. Cell-associated HIV-1 RNA in blood as indicator of viral load in lymph nodes. J Infect Dis 1999; 180: $850-3$.

29. Wong JK, Gunthard HF, Havlir DV, et al. Reduction of HIV-1 in blood and lymph nodes following potent antiretroviral therapy and the virologic correlates of treatment failure. Proc Natl Acad Sci USA 1997; 94 : 12574-9.

30. Opravil M, Cone RW, Fischer M, et al. Effects of early antiretroviral treatment on HIV-1 RNA in blood and lymphoid tissue: a randomized trial of double versus triple therapy. Swiss HIV Cohort Study. J Acquir Immune Defic Syndr 2000; 23:17-25.

31. Gunthard HF, Havlir DV, Fiscus S, et al. Residual human immunodeficiency virus (HIV) type 1 RNA and DNA in lymph nodes and HIV RNA in genital secretions and in cerebrospinal fluid after suppression of viremia for 2 years. J Infect Dis 2001; 183:1318-27.

32. Roge BT, Katzenstein TL, Gerstoft J. Comparison of P-triglyceride levels among patients with human immunodeficiency virus on randomized treatment with ritonavir, indinavir or ritonavir/saquinavir. Scand J Infect Dis 2001;33:306-11.

33. Ruiz L, Negredo E, Domingo P, et al. Antiretroviral treatment simplification with nevirapine in protease inhibitor-experienced patients with 
HIV-associated lipodystrophy: 1-year prospective follow-up of a multicenter, randomized, controlled study. J Acquir Immune Defic Syndr 2001;27:229-36.

34. Martinez E, Conget I, Lozano L, Casamitjana R, Gatell JM. Reversion of metabolic abnormalities after switching from HIV-1 protease inhibitors to nevirapine. AIDS 1999; 13:805-10.

35. Rachlis A, Becker S, Gill J, et al. Successful substitution of protease inhibitors with Sustiva (efavirenz) in patients with undetectable plasma HIV-1 RNA levels—results of a prospective, randomized, multicenter, open-label study (DMP266-049) [abstract 475]. In: Program and abstracts of the 40th Interscience Conference in Antimicrobial Agents and Chemotherapy (Toronto). Washington, DC: American Society for Microbiology, 2000:278.

36. Rey D, Schmitt MP, Partisani M, et al. Efavirenz as a substitute for protease inhibitors in HIV-1-infected patients with undetectable plasma viral load on HAART: a median follow-up of 64 weeks. J Acquir Immune Defic Syndr 2001;27:459-62.

37. Masquelier B, Neau D, Chene G, et al. Mechanism of virological failure after substitution of a protease inhibitor by nevirapine in patients with controlled HIV-1 RNA. Antiviral Ther 2000; 5(Suppl 3):94-5.

38. Raffi F, Bonnet B, Ferre V, et al. Substitution of a nonnucleoside reversetranscriptase inhibitor for a protease inhibitor in the treatment of patients with undetectable plasma human immunodeficiency virus type 1 RNA. Clin Infect Dis 2000;31:1274-8.

39. Martinez E, Romeu J, Garcia-Viejo MA, et al. An open randomized study on the replacement of HIV-1 protease inhibitors by efavirenz in chronically suppressed HIV-1-infected patients with lipodystrophy [abstract 668]. In: Program and abstracts of the 8th Conference on Retroviruses and Opportunistic Infections (Chicago). Alexandria, VA: Foundation for Retrovirology and Human Health, 2001:245. 